\title{
Immediate benefit of balloon aortic valvuloplasty in severe aortic stenosis: hemodynamic echographic assessment in Intensive Coronary Care Unit
}

Mihaela Calcaianu', Ulun Crimizade ${ }^{2}$, Nathan Messas ${ }^{2}$, Didier Bresson ${ }^{1}$, Jean-Yves Wiedemann ${ }^{1}$, Olivier Roth ${ }^{1}$, Michel Kindo ${ }^{3}$, Olivier Morel $^{2}$, Jacques Levy ${ }^{1}$, Laurent Jacquemin ${ }^{1}$ and Patrick Ohlmann ${ }^{2}$

${ }^{1}$ Cardiac Intensive Care Unit, Mulhouse Hospital, France

${ }^{2}$ Department of Cardiology, "Nouvel Hôpital Civil”, University of Strasbourg, France

${ }^{3}$ Department of Cardiac Surgery, 'Nouvel Hôpital Civil", University of Strasbourg, France

\begin{abstract}
Background: Balloon aortic valvuloplasty (BAV) might be a life saving procedure in critically advanced aortic stenosis (AS) as a bridge therapy to surgical aortic valve replacement (AVR) or to trans-catheter aortic heart valve (TAVI), by reducing trans-aortic gradient and increasing aortic valve area (AVA). Few is known on the benefit of BAV on cardiac output. Our study proposed to evaluate the hemodynamic changes after BAV by transthoracic echocardiography (TTE).

Methods: 30 consecutive patients with AS undergoing BAV were prospectively included between July 2014 and July 2015. Hemodynamic assessment was performed pre- and post-BAV by TTE. Low cardiac output (CO) was defined by a cardiac index (CI) $<2.5 \mathrm{~L} / \mathrm{min} / \mathrm{m}^{2}$.

Results: Mean age was $82 \pm 8$ years; 56.7\% were female; mean logistic EuroSCORE I was $31 \pm 19 \% .20$ patients (67\%) had low CO. TTE showed that the patients with low CO improved AVA (from $0.57 \pm 0.2$ to $1.05 \pm 0.5, \mathrm{p}=0.043$ ), CI (from $1.9 \pm 0.4$ to $2.8 \pm 1.0 \mathrm{~L} / \mathrm{min} / \mathrm{m}^{2}, \mathrm{p}<0.0001$ ), $\mathrm{LVEF}$ (from $31 \pm 16$ to $38 \pm 13 \%$, $\mathrm{p}=0.006$ ), tend to decrease systolic pulmonary artery pressure (sPAP) (from $52 \pm 19$ to $43 \pm 11 \mathrm{mmHg}, \mathrm{p}=0.06$ ) and to increase mean arterial pressure (MAP) (from $79 \pm 10$ to $83 \pm 12 \mathrm{mmHg}, \mathrm{p}=0.046)$. There was no statistically significant difference in terms of hemodynamic in patients with a normal CO $\left(\mathrm{CI} \geq 2.5 \mathrm{~L} / \mathrm{min} / \mathrm{m}^{2}\right)$.
\end{abstract}

Conclusion: By increasing AVA, BAV significantly and immediately improve cardiac output especially in patients with low CO at baseline.

\section{Introduction}

Balloon aortic valvuloplasty (BAV) was first suggested in 1986 by Cribier as an alternative to surgical aortic valve replacement in patients with severe aortic stenosis (AS) [1]. The BAV procedure was correlated with significant morbidity and mortality [2] and after an initial peak, BAV usage decreased dramatically, being reserved for palliative indications.

The introduction of transcatheter aortic valve replacement (TAVR) led to restarted interest in BAV especially in the United States [3].

Historically, the early results of BAV were disappointing [4,5]. Nevertheless, upgraded technology, including lower profile balloons, and especially the use of rapid temporary pacing during balloon inflation, together with vaster operator experience has led to the enhancement of this procedure.

Although there are no definite recommendations, BAV should be considered in the following clinical scenarios: bridge to destination procedure (AVR/TAVR), rescue procedure in patients with lifethreatening clinical conditions, as a palliative measure in high-risk or inoperable patients, before urgent non-cardiac surgery (ex: hip fracture), critically ill patients with short anticipated survival (ex: cancer), diagnostic test in low gradient /low output situation, in symptomatic pregnant women (bridge to delivery) [6].

In contemporary practice, BAV may offer especially a bridge to definitive replacement of the valve or can be used in an elderly fragile high-risk patient with severe aortic stenosis in whom the role of TAVI is uncertain or inappropriate [7]. So BAV may be a real treatment strategy, either as a bridge to definitive therapy or as a palliative procedure, with an acceptable mortality rate. BAV is associated with a significant improvement in symptoms and is valuable as a palliative treatment in high-risk patients, where no other invasive option is available [8].

Especially that the patients with severe AS accompanied by congestive heart failure (CHF) have a poor prognosis if not treated with aortic valve replacement. In the presence of severe left ventricular (LV) dysfunction, the prognosis is even worse.

Otto, et al. described the 3-year outcome in 674 patients enrolled in the National Heart, Lung, and Blood Institute's registry [9]. In these patients undergoing BAV with mild, moderate, and severe LV systolic dysfunction, the 1 -year survival rate was $59 \%, 50 \%$, and $26 \%$, respectively.

*Correspondence to: Calcaianu M, Unité de Soins Intensifs Cardiologiques, Hôpital Emile Muller 20, Avenue du Dr. René Laennec, 68100 Mulhouse, France, Tel: +33 896464 64; Fax: +33 896479 11; E-mail: calcaianu.mihaela@gmail.com

Key words: severe aortic stenosis, balloon aortic valvuloplasty, transcatheter aortic valve replacement

Received: September 16, 2018; Accepted: September 25, 2018; Published: September 28, 2018 
Pedersen, et al. determined the outcomes following BAV in AS patients with a left ventricular ejection fraction (LVEF) $<20 \%$ and suggested that with appropriate technique, BAV can be reasonably safe in patients with LVEF $<20 \%$. Roughly half of these patients showed improvement in LVEF to $\geq 20 \%$ [10].

Nevertheless, little is known on the benefit of BAV on cardiac output.

The aim of this study was to evaluate the hemodynamic changes after BAV by transthoracic echocardiography (TTE) in AS patients in Intensive Coronary Care Unit and to determine the outcomes following $\mathrm{BAV}$ in these patients.

\section{Methods}

\section{Study design}

From July 2014 to July 2015, the data from 148 consecutive patients with severe symptomatic AS were prospectively included into a dedicated database at our institution. Of these, 118 (80\%) patients underwent directly TAVR procedure. Of the remaining $30(20 \%)$ patients underwent BAV procedure on initial therapy. The study population flowchart is represented in Figure 1. Patients underwent a multi-disciplinary heart team assessment before being declined for TAVI or SAVR due to unacceptably high risks or contraindications. Clinical, echocardiographic, hemodynamic, and follow-up mortality data were collected.

Overall, our cohort consisted of 30 patients evaluated in one single-center. All patients had severe, symptomatic AS confirmed by transthoracic echocardiography and hemodynamic assessment. Patients were referred for BAV for palliation of heart failure symptoms, treatment of cardiogenic shock, and, as a bridge for TAVI/SAVR.

Little is known on the benefit of BAV on cardiac output (CO). The analysis was performed according to $\mathrm{CO}$ for the purpose of understanding procedural safety and outcomes. The logistic EuroSCORE (European System for Cardiac Operative Risk Evaluation) was calculated for all patients.

In-hospital echocardiographic, hemodynamic outcomes and clinical events were determined. Follow-up was obtained by trained medical personnel using direct telephone interviews and review of

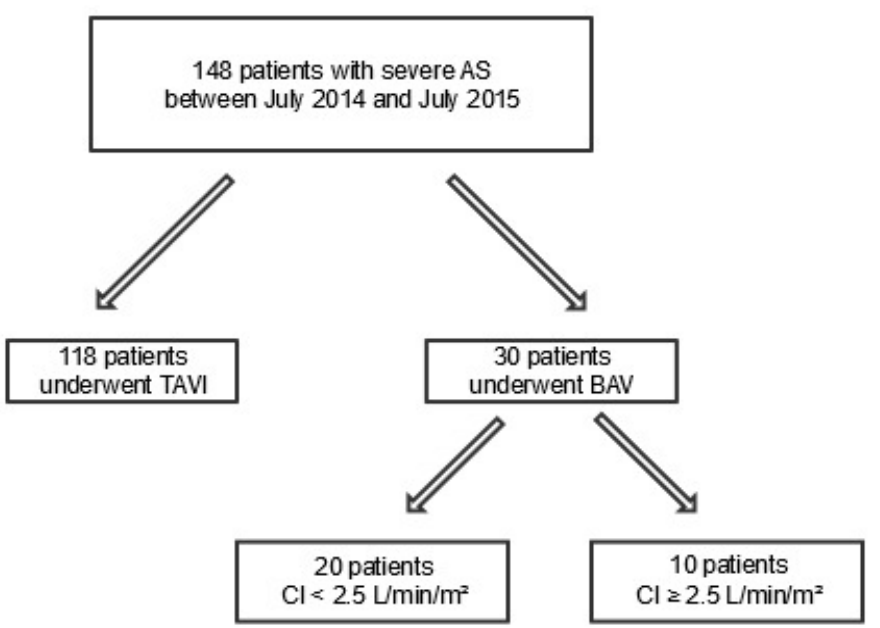

Figure 1. Study population flowchart. AS = aortic stenosis; TAVI = transcatheter aortic valve implantation; $\mathrm{BAV}=$ balloon aortic valvuloplasty; $\mathrm{CI}=$ cardiac index medical records both in-hospital and during follow-up outpatient physician visits.

\section{Preprocedural monitoring}

Preprocedural monitoring was considered the day before BAV in Intensive Coronary Care Unit (ICCU).

NYHA class was determined at baseline.

Pre-operative aortic valve (AV) mean gradient, aortic valve area (AVA), left ventricular ejection fraction (LVEF), cardiac index (CI), pulmonary artery systolic pressure (sPAP) were obtained from echocardiographic evaluation performed the day before BAV.

Also, hemodynamic monitoring was assessed the day before BAV in ICCU: heart rate (HR), mean arterial pressure (MAP), right atrial pressure (RAP) and central venous pressure (CVP) estimation using assessment of the inferior vena cava indices [11], systemic vascular resistance (SVR). SVR was obtained using the formula: $80 \mathrm{x}$ (MAPCVP)/CO [12].

\section{Procedure - balloon aortic valvuloplasty}

BAV was performed by established retrograde technique [13]. A low-dose heparin bolus was administered in all patients (usually $50 \mathrm{IU} /$ $\mathrm{kg}$ ). The mean arteriotomy sheath size was $12 \mathrm{~F}$ for Nucleus-X balloon.

Balloon size selection was based up on information from cardiac computed tomography. AV mean gradients were re-measured after one to three inflations, obtaining a $50 \%$ reduction. If necessary, additional balloon inflations were carried out with a larger diameter balloon.

Rapid ventricular pacing was utilized (via the right ventricle), vascular closure using the Angio-Seal closure system (St Jude Medical), ProGlide device (Abbott Vascular) or managed with manual compression. Postprocedural monitoring

Postprocedural monitoring was considered at 72 hours after BAV in ICCU.

NYHA class was re-evaluated.

Post-operative AV mean gradient, AVA, LVEF, CI, sPAP were obtained from echocardiographic evaluation performed by the same echocardiographer.

Similarly, hemodynamic monitoring was assessed after BAV: HR, MAP, RAP and CVP estimation, SVR.

\section{Definitions}

Severe AS was defined as an estimated aortic valve area of less than $1 \mathrm{~cm} 2$ (by continuity equation), a mean transvalvular gradient of at least $40 \mathrm{mmHg}$, or a peak aortic velocity of at least $4 \mathrm{~m} / \mathrm{s}$ [14].

Low cardiac output (CO) was defined by a $\mathrm{CI}<2.5 \mathrm{~L} / \mathrm{min} / \mathrm{m} 2$.

Individual logistic Euro SCOREs were calculated to provide an approximate estimate of perioperative mortality rate [15].

Chronic kidney disease (CKD) was defined as moderate/severe when the estimated glomerular filtration rate (GFR) was less than 50 $\mathrm{mL} / \mathrm{min}$ [16].

Cardiogenic shock was characterised by systolic blood pressure < $90 \mathrm{mmHg}$ with tissue hypoperfusion or requirement for inotropes.

Procedural success was definite by at least one balloon inflation with a measured diminution in the invasively measured gradient 
across the aortic valve without occurrence of a major intraprocedural complication.

Major intraprocedural complications were defined as death within 24 hours of procedure, new severe aortic regurgitation, myocardial infarction, stroke, tamponade, and major vascular complications [7].

\section{Patient subgroup analysis}

Our 30 patients were divided into two groups based on preoperative IC. Group 1 of patients had low IC $\left(<2.5 \mathrm{~L} / \mathrm{min} / \mathrm{m}^{2}\right)$ and group 2 of patients included all subjects whose preoperative IC $\geq 2.5 \mathrm{~L} / \mathrm{min} /$ $\mathrm{m}^{2}$. Variables associated with improvement in IC were determined by comparison of each group's clinical, echocardiographic, and hemodynamic findings.

\section{Statistical analysis}

Analyses were performed using SPSS, version 20. Continuous variables are presented as mean \pm SD and categorical variables are presented as percentages. Significant differences at baseline, between the 2 subgroups $\left(\mathrm{CI}<2.5 \mathrm{~L} / \mathrm{min} / \mathrm{m}^{2}\right.$ vs. $\left.\mathrm{CI} \geq 2.5 \mathrm{~L} / \mathrm{min} / \mathrm{m}^{2}\right)$, defined in the results section, were determined using the Mann-Whitney U-test. Correlation coefficients were calculated using Spearman test. Categorical variables were compared using the chi-square test or the Fisher exact test as indicated. After confirming non-Gaussian distribution, paired sample Wilcoxon rank tests were applied to echocardiographic and hemodynamic variables before and after BAV. Cumulative survival curves were constructed using the Kaplan-Meier method and the survival rates were compared using the Log Rank test. Significance was set at $\mathrm{p}<0.05$.

\section{Results}

The indications for BAV from our series of 30 consecutive procedures in 30 individual patients are represented in Figure 2. The mains indications for BAV in our cohort were for palliation of symptoms in congestive heart failure $\mathrm{n}=19(64 \%)$, symptom relief in cardiogenic shock $\mathrm{n}=6(20 \%)$. Other indications included bridge to TAVI $\mathrm{n}=4(13 \%)$ and bridge to non-cardiac surgery $n=1(3 \%)$.

Baseline patient characteristics are listed in Table 1. They reflect a high surgical risk with a mean age of $82 \pm 8$ years and a mean logistic EuroSCORE of $31 \pm 19 \%$. 56.7\% were female. All patients were symptomatic, with the majority of them (53.3\%) in New York Heart Association (NYHA) classification IV heart failure. For the majority of the patients $(60 \%), \mathrm{BAV}$ was a vital emergency procedure in the first hours after ICCU admission.

Baseline echocardiographic and hemodynamic findings are listed in Table 2. TTE the day before BAV find that 20 patients (67\%) had low CO. The mean LVEF was $31 \pm 16 \%$ for these patients and $53 \pm 18 \%$ for the patients with normal CO. AV mean gradient was $37 \pm$ $16 \mathrm{mmHg}$ for low $\mathrm{CO}$ and $50 \pm 6 \mathrm{mmHg}$ for normal $\mathrm{CO}$ respectively. AVA was $0.57 \pm 0.2 \mathrm{~cm} 2$ versus $0.64 \pm 0.2 \mathrm{~cm}^{2}$. In terms of SVR, RAP, MAP, HR, BNP the two groups were almost comparable.

Postprocedural echocardiographic and hemodynamic results are summarized in Table 3. TTE at 72 hours showed that the patients with low CO improved AVA (from $0.57 \pm 0.2$ to $1.05 \pm 0.5 \mathrm{~cm}^{2}$, $\mathrm{p}=0.043$ ), CI (from $1.9 \pm 0.3$ to $2.8 \pm 1.0 \mathrm{~L} / \mathrm{min} / \mathrm{m}^{2}, \mathrm{p}<0.0001$ ) (Figure 3 ) and LVEF (from $31 \pm 16$ to $38 \pm 13 \%, p=0.006$ ). These patients tend to decrease sPAP, from $52 \pm 19$ to $43 \pm 11 \mathrm{mmHg}, \mathrm{p}=0.06$, and to increase MAP, from $79 \pm 10$ to $83 \pm 12 \mathrm{mmHg}, \mathrm{p}=0.046$. There was no statistically significant difference in terms of hemodynamic in patients with a normal $\mathrm{CO}\left(\mathrm{CI} \geq 2.5 \mathrm{~L} / \mathrm{min} / \mathrm{m}^{2}\right)$. After the $\mathrm{BAV}$, for the

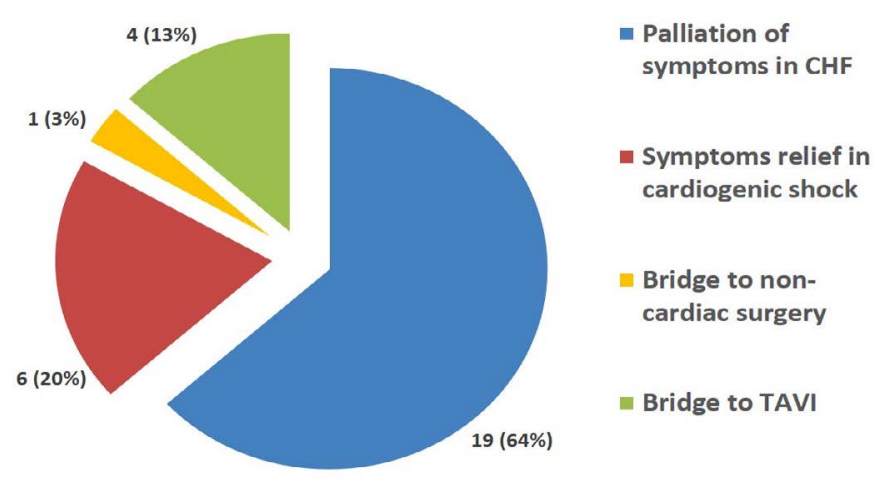

Figure 2. Indications for BAV. $\mathrm{CHF}=$ congestive heart failure; $\mathrm{TAVI}=$ transcatheter aortic valve implantation; $\mathrm{BAV}=$ balloon aortic valvuloplasty

Table 1. Baseline patients' characteristics; BMI = body mass index; NYHA = New York Heart Association; $\mathrm{BNP}=$ brain natriuretic peptide; $\mathrm{GFR}=$ glomerular filtration rate

\begin{tabular}{|l|l|l|l|}
\hline & $\begin{array}{l}\mathbf{C I}<\mathbf{2 . 5} \mathbf{~} / \\
\mathbf{m i n} / \mathbf{m}^{2} \\
\mathbf{N = 2 0}\end{array}$ & $\begin{array}{l}\mathbf{C I} \geq \mathbf{2 . 5} \mathbf{~ L} / \\
\mathbf{m i n} / \mathbf{m}^{\mathbf{2}} \\
\mathbf{N = 1 0}\end{array}$ & $\begin{array}{l}\mathbf{p} \\
\text { value }\end{array}$ \\
\hline Age (years) & $82 \pm 5$ & $81 \pm 12$ & 0.69 \\
\hline Male sex (\%) & $10(50)$ & $3(42)$ & 0.26 \\
\hline Logistic EuroSCORE (\%) & $34 \pm 21$ & $24 \pm 15$ & 0.39 \\
\hline BMI (Kg/m $)$ & $26 \pm 4$ & $25 \pm 8$ & 0.51 \\
\hline Previous unsuccessful TAVI & $1(5)$ & $1(10)$ & 0.56 \\
\hline Peripheral vascular disease (\%) & $5(25)$ & $1(10)$ & 0.32 \\
\hline Coronary artery disease (\%) & $10(50)$ & $2(20)$ & 0.11 \\
\hline Mitral regurgitation (\%) & $2(10)$ & $1(10)$ & 0.74 \\
\hline Atrial fibrillation (\%) & $6(33)$ & $4(40)$ & 0.44 \\
\hline Active malignancy (\%) & $0(0)$ & $1(10)$ & \\
\hline NYHA class II/III & $6(33)$ & $7(70)$ & 0.08 \\
\hline NYHA class IV (\%) & $14(66)$ & $3(30)$ & 0.08 \\
\hline Cardiogenic shock (\%) & $6(33)$ & $7(70)$ & 0.03 \\
\hline BNP (pg/mL) & $1416 \pm 1404$ & $1722 \pm 1900$ & 0.68 \\
\hline GFR (mL/min) & $49 \pm 17$ & $52 \pm 22$ & 0.26 \\
\hline GFR < 30 mL/min (\%) & $4(20)$ & $3(30)$ & 0.42 \\
\hline Vital emergency BAV & $6(33)$ & $6(60)$ & 0.11 \\
\hline
\end{tabular}

Table 2. Baseline hemodynamic findings $; \mathrm{CI}=$ cardiac index; $\mathrm{LVEF}=$ left ventricular ejection fraction; $\mathrm{AV}=$ aortic valve; $\mathrm{AVA}=$ aortic valve area; $\mathrm{sPAP}=$ systolic pulmonary artery pressure; $\mathrm{RAP}=$ right atrial pressure; $\mathrm{MAP}=$ mean arterial pressure; $\mathrm{HR}=$ heart rate; $\mathrm{BPM}=$ beats per minute; $\mathrm{SVR}=$ systemic vascular resistance

\begin{tabular}{|c|c|c|c|c|}
\hline & $\begin{array}{l}\text { All patients } \\
\mathbf{N}=\mathbf{3 0}\end{array}$ & $\begin{array}{l}\mathrm{CI}<2.5 \mathrm{~L} / \\
\mathbf{m i n} / \mathbf{m}^{2} \\
\mathrm{~N}=\mathbf{2 0}\end{array}$ & $\begin{array}{l}\mathrm{CI} \geq 2.5 \mathrm{~L} / \\
\mathrm{min} / \mathrm{m}^{2} \\
\mathrm{~N}=10\end{array}$ & $p$ value \\
\hline LVEF (\%) & $39 \pm 20$ & $31 \pm 16$ & $53 \pm 18$ & 0.004 \\
\hline $\begin{array}{l}\text { AV mean gradient } \\
(\mathrm{mmHg})\end{array}$ & $42 \pm 15$ & $37 \pm 16$ & $50 \pm 6$ & $<0.0001$ \\
\hline $\operatorname{AVA}\left(\mathrm{cm}^{2}\right)$ & $0.64 \pm 0.2$ & $0.57 \pm 0.2$ & $0.64 \pm 0.2$ & 0.005 \\
\hline SPAP (mmHg) & $49 \pm 17$ & $52 \pm 19$ & $45 \pm 10$ & 0.510 \\
\hline RAP (mmHg) & $9 \pm 6$ & $10 \pm 6$ & $9 \pm 6$ & 0.480 \\
\hline MAP (mmHg) & $80 \pm 11$ & $79 \pm 10$ & $83 \pm 14$ & 0.35 \\
\hline HR (BPM) & $80 \pm 15$ & $80 \pm 16$ & $81 \pm 13$ & 0.92 \\
\hline SVR(dynes $\left.\cdot \sec \cdot \mathrm{cm}^{-5}\right)$ & $1550 \pm 750$ & $1750 \pm 800$ & $1160 \pm 450$ & 0.025 \\
\hline BNP $(p g / m L)$ & $1530 \pm 1576$ & $1416 \pm 1404$ & $1722 \pm 1900$ & 0.68 \\
\hline $\begin{array}{l}\text { Peak-to-peak gradient } \\
\text { (mmHg) }\end{array}$ & $40 \pm 15$ & $44 \pm 14$ & $58 \pm 13$ & 0.015 \\
\hline
\end{tabular}

patients with low $\mathrm{CO}$, the mean increase in valve area was $0.5 \pm 0.45$ $\mathrm{cm}^{2}$ higher compared with the group with normal $\mathrm{CO}$, with a mean increase in AVA only $0.3 \pm 0.43 \mathrm{~cm}^{2}(\mathrm{p}=0.041)$. By increasing AVA, BAV significantly and immediately improve cardiac output especially in patients with low $\mathrm{CO}$ at baseline. 

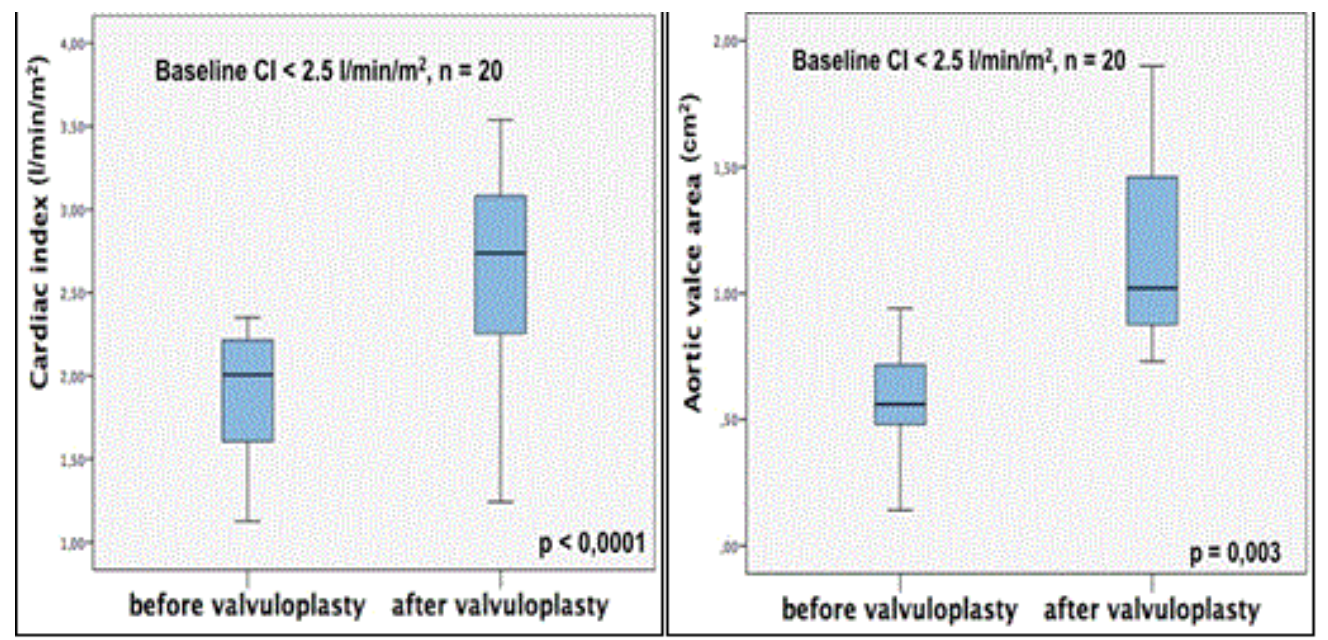

Figure 3. Changes in CI and AVA after BAV. CI = cardiac index; AVA = aortic valve area; BAV = balloon aortic valvuloplasty

\section{Complication}

The procedure was technically successful in all cases with no intraprocedural deaths (within 24 hours of BAV). Major and minor associated complications are outlined in Table 4. Myocardial infarction occurred in two patients (6.6\%) requiring revascularization. Periprocedural ventricular arrhythmias happened in three cases $(3.9 \%)$ with successful resuscitation for these patients. Major vascular access site or access-related complications occurred in 7 participants (23\%). No patients had a conduction disease stroke, tamponade or developed new severe AR during the 30-day follow-up. Persistence of congestive heart failure or rehospitalization followed in 9 participants (30\%).

\section{Outcomes and mortality}

In terms of definitive treatment, 8 patients underwent TAVI and 1 patient suffered SAVR. All the patients, from whom BAV procedure was completed by TAVI or SAVR, presented a low CI (Table 5).

In our cohort of patients with severe AS treated by BAV, 15 patients (50\%) died (including all causes of death) during the study period. The mortality in the first month was $20 \%$ ( 6 patients). The median duration of the follow-up was 271 days (range $=4-1049$ days). The median survival was 9,6 months (95\% confidence interval 5,1-14; Figure 4). Results of the univariate analysis are presented in Table 6.

We found that patients treated by BAV and TAVI/SAVR had a better survival than those who didn't receive TAVI/SAVR $(p=0,035$; Figure 5). However, this is no longer significant after multivariate analysis (Table 7). There is no difference in terms of survival for the patients with low CI versus normal CI $(\log$-rank $\mathrm{p}=0.16)$.

\section{Discussion}

This study describes the outcomes following BAV in our cohort according to cardiac index. Little is known on the benefit of BAV on cardiac output.

There are no differences in clinical status in the patients with low CI vs. normal CI. Although, in terms of baseline echocardiographic features, we found differences between the two groups, with a significant lower LVEF and AVA and higher AV mean gradient. Relating to baseline hemodynamic presentation, there are no differences.

We observed that the patients with low $\mathrm{CI}$ at baseline could benefit more from BAV procedure than those with normal CI.
Table 3. Changes in hemodynamic findings after $\mathrm{BAV} ; \mathrm{CI}=$ cardiac index; $\mathrm{AV}=$ aortic valve; $\mathrm{AVA}=$ aortic valve area; $\mathrm{SPAP}=$ systolic pulmonary artery pressure; $\mathrm{RAP}=$ right atrial pressure; $\mathrm{MAP}=$ mean arterial pressure; $\mathrm{HR}=$ heart rate; $\mathrm{BPM}=$ beats per minute $\mathrm{SVR}=$ systemic vascular resistance

\begin{tabular}{|c|c|c|c|c|c|c|}
\hline & \multicolumn{2}{|c|}{$\begin{array}{l}\text { Baseline } \\
\mathrm{CI}<2.5 \mathrm{~L} / \mathrm{min} / \mathrm{m}^{2} \\
\mathrm{~N}=\mathbf{2 0}\end{array}$} & \multirow{2}{*}{$\begin{array}{l}\mathbf{p} \\
\text { value }\end{array}$} & \multicolumn{2}{|c|}{$\begin{array}{l}\text { Baseline } \\
C I \geq 2.5 \mathrm{~L} / \mathrm{min} / \mathrm{m}^{2} \\
\mathrm{~N}=10\end{array}$} & \multirow{2}{*}{$\begin{array}{l}p \\
\text { value }\end{array}$} \\
\hline & $\begin{array}{l}\text { Before } \\
\text { BAV }\end{array}$ & $\begin{array}{l}\text { After } \\
\text { BAV }\end{array}$ & & Before BAV & $\begin{array}{l}\text { After } \\
\text { BAV }\end{array}$ & \\
\hline LVEF (\%) & $31 \pm 16$ & $38 \pm 13$ & 0.006 & $53.7 \pm 18.4$ & $51 \pm 18$ & 0.65 \\
\hline $\begin{array}{l}\text { AV mean } \\
\text { gradient (mmHg) }\end{array}$ & $37 \pm 16$ & $22.2 \pm 8.1$ & $<0.0001$ & $49.80 \pm 6$ & $29.8 \pm 6.4$ & 0.008 \\
\hline $\operatorname{AVA}\left(\mathrm{cm}^{2}\right)$ & $0.57 \pm 0.2$ & $1.05 \pm 0.5$ & 0.043 & $0.8 \pm 0.1$ & $1.08 \pm 0.5$ & 0.22 \\
\hline CI $\left(1 / \mathbf{m i n} / \mathbf{m}^{2}\right)$ & $1.9 \pm 0.4$ & $2.8 \pm 1.0$ & $<0.0001$ & $3.14 \pm 0.99$ & $3.1 \pm 0.66$ & 0.77 \\
\hline sPAP (mmHg) & $52 \pm 19$ & $43 \pm 11$ & 0.06 & $50.2 \pm 10$ & $49 \pm 33$ & 0.46 \\
\hline RAP (mmHg) & $10 \pm 6$ & $9 \pm 6$ & 0.49 & $8.5 \pm 6.2$ & $9.4 \pm 10.5$ & 0.41 \\
\hline MAP (mmHg) & $79 \pm 10$ & $83 \pm 12$ & 0.046 & $83 \pm 14$ & $91 \pm 12$ & 0.36 \\
\hline HR (BPM) & $80 \pm 16$ & $83 \pm 14$ & 0.63 & $81 \pm 13$ & $80 \pm 9$ & 0.73 \\
\hline $\begin{array}{l}\text { SVR } \\
\left(\text { dynes } \cdot \sec \cdot \mathrm{cm}^{-5}\right)\end{array}$ & $1746 \pm 800$ & $1420 \pm 957$ & 0.06 & $1160 \pm 450$ & $1585 \pm 822$ & 0.09 \\
\hline BNP $(\mathrm{pg} / \mathrm{mL})$ & $1416 \pm 1404$ & $1094 \pm 1178$ & 0.11 & $1722 \pm 1900$ & $956 \pm 1214$ & 0.017 \\
\hline $\begin{array}{l}\text { Peak-to-peak } \\
\text { gradient (mmHg) }\end{array}$ & $44 \pm 14.4$ & $19.3 \pm 8$ & $<0.0001$ & $58.1 \pm 12.9$ & $25 \pm 6$ & 0.005 \\
\hline
\end{tabular}

Table 4. 30-Day Complications after BAV

\begin{tabular}{|l|c|}
\hline & N (\%) \\
\hline Intraprocedural death (<24 hours) & 0 \\
\hline Death (30-day mortality) & 3 \\
\hline Stroke & 0 \\
\hline Myocardial infarction & 2 \\
\hline Cardiac tamponade & 0 \\
\hline Severe aortic regurgitation & 0 \\
\hline Pacemaker insertion & 0 \\
\hline Major vascular complication & 7 \\
\hline Recovery from cardiac arrest & 3 \\
\hline Congestive heart failure & 9 \\
\hline
\end{tabular}

Table 5. Outcomes after BAV; $\mathrm{CI}=$ cardiac index; $\mathrm{BAV}=$ balloon aortic valvuloplasty; TAVI $=$ transcatheter aortic valve implantation; SAVR = surgical aortic valve replacement

\begin{tabular}{|l|l|l|l|l|}
\hline $\begin{array}{l}\text { Bridging BAV } \\
\text { to }\end{array}$ & $\begin{array}{l}\text { All patients } \\
\mathbf{N}=\mathbf{3 0}\end{array}$ & $\begin{array}{l}\text { Baseline } \\
\mathbf{C I}<\mathbf{2 . 5} \mathbf{l} / \mathbf{m i n} / \mathbf{m}^{2} \\
\mathbf{N}=\mathbf{2 0}\end{array}$ & $\begin{array}{l}\text { Baseline } \\
\mathbf{C I} \geq \mathbf{2 . 5} \mathbf{l} / \mathbf{m i n} / \mathbf{m}^{2} \\
\mathbf{N}=\mathbf{1 0}\end{array}$ & p value \\
\hline TAVI (\%) & $8(27)$ & $8(40)$ & 0 & 0.041 \\
\hline SAVR (\%) & $1(3)$ & $1(5)$ & 0 & 0.71 \\
\hline
\end{tabular}




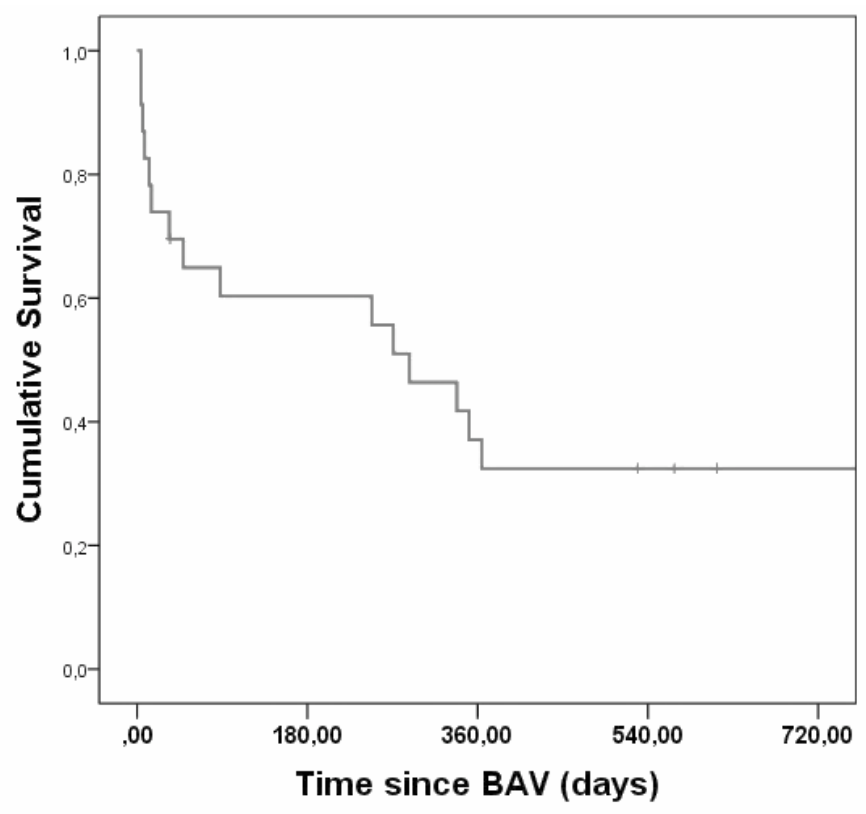

Figure 4. Kaplan-Meyer Survival Curves of patients undergoing BAV

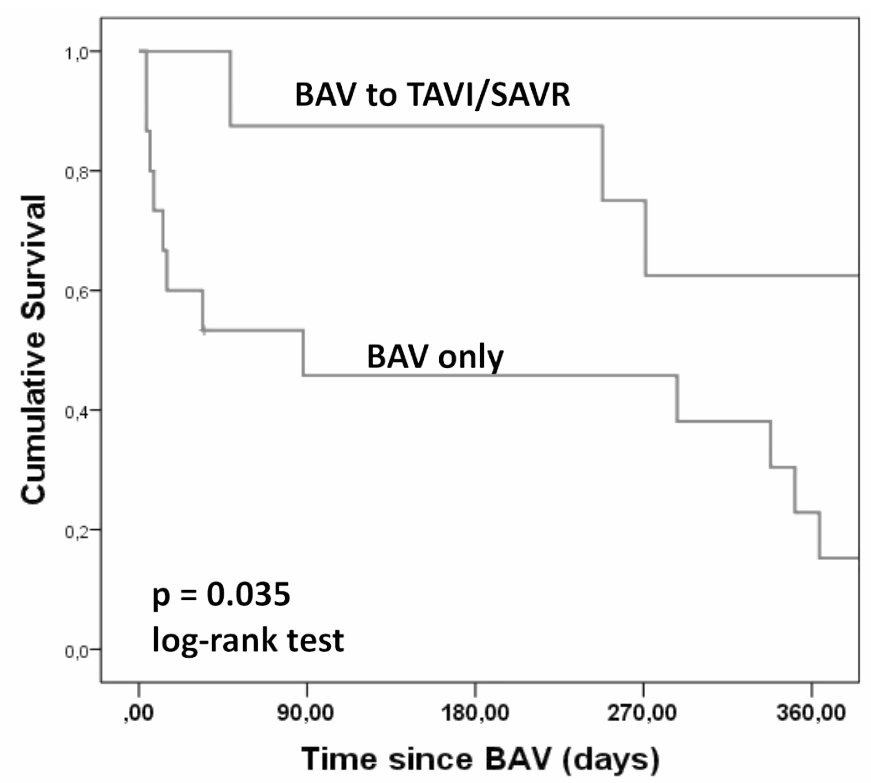

Figure 5. Kaplan-Meyer Survival Curves of patients undergoing BAV only versus bridge to TAVI or SAVR

Table 6. Univariate analysis of factors associated with mortality; TAVI $=$ transcatheter aortic valve implantation; $\mathrm{CI}=$ cardiac index; $\mathrm{LVEF}=$ left ventricular ejection fraction; $\mathrm{AVA}=$ aortic valve area; GFR $=$ glomerular filtration rate

\begin{tabular}{|l|c|}
\hline Variable & p value \\
\hline TAVI post BAV & 0.035 \\
\hline IC $<\mathbf{2 . 5} \mathbf{~ L / m i n} / \mathbf{m}^{\mathbf{2}}$ & 0.16 \\
\hline $\mathbf{L V E F}<\mathbf{5 0} \%$ & 0.61 \\
\hline GFR $<\mathbf{3 0} \mathbf{~} \mathbf{L} / \mathbf{m i n}$ & 0.36 \\
\hline Improving IC & 0.76 \\
\hline AVA post BAV $>\mathbf{1 c m}^{\mathbf{2}}$ & 0.32 \\
\hline
\end{tabular}

Table 7. Multivariate analysis of factors associated with mortality

\begin{tabular}{|l|l|l|l|}
\hline Variable & HR & $\mathbf{9 5 \%}$ CI & P value \\
\hline TAVI & 0,304 & $0,078-1,181$ & 0,086 \\
\hline IC $<\mathbf{2 . 5} \mathbf{~ L / m i n} / \mathbf{m}^{\mathbf{2}}$ & 1,278 & $0,400-4,082$ & 0,679 \\
\hline
\end{tabular}

\section{Acute outcomes after BAV}

Transthoracic echocardiography carried out in ICCU at 72 hours showed that the patients with low CO improved AVA (from $0.6 \pm 0.2$ to $1.05 \pm 0.5 \mathrm{~cm}^{2}, \mathrm{p}=0.043$ ), CI (from $1.9 \pm 0.3$ to $2.8 \pm 1.0 \mathrm{~L} / \mathrm{min} / \mathrm{m}^{2}$, $\mathrm{p}<0.0001$ ) and LVEF (from $31 \pm 16$ to $38 \pm 13 \%, \mathrm{p}=0.006$ ). There was no statistically significant difference in patients with a normal CO (CI $\geq 2.51 / \mathrm{min} / \mathrm{m} 2$ ). In addition, we found that after BAV, the patients with low CO showed a higher increase in valve area (mean value 0.5 $\pm 0.45 \mathrm{~cm}^{2}$ ) than those patients with normal CO (mean value $0.3 \pm$ $\left.0.43 \mathrm{~cm}^{2}\right)(\mathrm{p}=0.041)$. Therefore, by increasing AVA, BAV significantly improved cardiac output, especially in patients with low $\mathrm{CO}$ at baseline. Furthermore, the overall change in AVA in our study for these patients is higher than was previously reported in some series $[17,18]$ and in accordance with other study [19]. Although this improvement was statistically significant, the difference was not correlated with a better survival rate.

TAVI has become a reputable alternative treatment for patients considered too high risk for conventional surgery. The PARTNER 1 trial described a reduction in mortality and symptomatic improvement in TAVI patients, when compared to standard conservative therapy [20]. An increasing number of TAVI implantations has led to a revival of BAV mainly as this constitutes part of the TAVI procedure, in many centres [21].

BAV has both proponents and opponents. Our study shows the application of the current clinical guidelines for BAV [14] to a real cohort of patients. Unlike previous studies we offered BAV as a bridge to definitive therapy in 9 (30\%) of our patients, as opposed to $15 \%$ conversion or less in other series $[17,19]$. This can be explained in part by the availability of TAVI procedure, which is now performed with an increasing frequency, and therefore, we were able to propose this option to greater numbers of patients, than in those previous studies that reflected previous practices. This sub-group of 9 patients was too poor for definitive treatment initially, but BAV facilitated that. The most remarkable illustration of this lies in these 9 patients with low CI who went forward to successful destination therapy (8 patients for TAVI and 1 patient for SAVR).

With appropriate technique, BAV was performed without intraprocedural mortality. Our study shows that BAV offers a relatively safe procedure allowing immediate haemodynamic benefit in ICCU especially in patients with low CI.

\section{Long-term outcomes after BAV}

In our cohort of patients with severe AS treated by BAV, 15 patients (50\%) died (including all causes of death) during the study period. This observation is in accordance with rates previously reported $[9,17,18]$.

We found that patients treated by BAV and TAVI/SAVR had a better survival than those who didn't receive TAVI/SAVR $(\mathrm{p}=0.035)$. Long-term survival after definitive therapy post-BAV was already described in prior studies $[8,17,19]$. However, this is no longer significant after multivariate analysis. These findings could suggest the possibility of still using BAV in management of sever AS with poor prognosis.

In contrast, there is no difference in terms of survival for the patients with low CI versus normal CI (log-rank $\mathrm{p}=0.16)$. Our study therefore confirmed that BAV remained only a brief temporary strategy with a poor long-term outcome without sequent definitive therapy according to the results of the standard therapy group in the randomized PARTNER 1 inoperable cohort [22]. 


\section{Study limitations}

Limitations arise from the small patient numbers treated in a single centre. The data is observational without randomisation.

\section{Conclusion}

The results of our work suggest that BAV offers a relatively safe procedure allowing immediate haemodynamic benefit in ICCU especially in patients with low CI. By increasing AVA, BAV significantly improve cardiac output especially in patients with low CO at baseline.

Our study therefore confirmed that BAV remained only a brief temporary strategy with a poor long-term outcome without sequent definitive therapy, because the patients treated by BAV and TAVI/SAVR had a better survival rate than those who didn't receive TAVI/SAVR.

\section{Disclosures}

None.

\section{References}

1. Cribier A, Savin T, Saoudi N, Rocha P, Berland J, et al. (1986) Percutaneous transluminal valvuloplasty of acquired aortic stenosis in elderly patients: an alternative to valve replacement? Lancet Lond Engl 1: 63-67.

2. No author Listed (1991) Percutaneous balloon aortic valvuloplasty. Acute and 30-day follow-up results in 674 patients from the NHLBI Balloon Valvuloplasty Registry. Circulation 84: 2383-2397.

3. Alkhouli M, Zack CJ, Sarraf M, Bashir R, Nishimura RA, et al. (2017) Morbidity and Mortality Associated With Balloon Aortic Valvuloplasty: A National Perspective. Circ Cardiovasc Interv 10: e004481.

4. Holmes DR, Nishimura RA, Reeder GS (1991) In-hospital mortality after balloon aortic valvuloplasty: frequency and associated factors. J Am Coll Cardiol 17: 189-192.

5. Reeder GS, Nishimura RA, Holmes DR (1991) Patient age and results of balloon aortic valvuloplasty: the Mansfield Scientific Registry experience. The Mansfield Scientific Aortic Valvuloplasty Registry Investigators. J Am Coll Cardiol 17: 909-913.

6. Vinotha V, Jose R (2012) Balloon aortic valvuloplasty in pregnancy with severe aortic stenosis and infective endocarditis. Int J Reprod Contracept Obstet Gynecol pp. 69-71.

7. Ford TJ, Nguyen K, Brassil J, Kushwaha V, Friedman D, et al. (2017) Balloon Aortic Valvuloplasty in The Transcatheter Valve Era: Single Centre Indications And Early Safety Data in A High Risk Population. Heart Lung Circ.

8. Sandhu K, Krishnamoorthy S, Afif A, Nolan J, Gunning MG (2017) Balloon aortic valvuloplasty in contemporary practice. J Interv Cardiol 30: 212-216. [Crossref]

9. Otto CM, Mickel MC, Kennedy JW, Alderman EL, Bashore TM (1994) Three-year outcome after balloon aortic valvuloplasty. Insights into prognosis of valvular aortic stenosis. Circulation 89: 642-650. [Crossref]
10. Pedersen WR, Goldenberg IF, Pedersen CW, Lesser A, Harris KM, et al. (2014) Balloon aortic valvuloplasty in high risk aortic stenosis patients with left ventricular ejection fractions $<20 \%$ : Aortic Valvuloplasty in Severe LV Dysfunction. Catheter Cardiovasc Interv 84: 824-831.

11. Beigel R, Cercek B, Luo H, Siegel RJ (2013) Noninvasive evaluation of right atrial pressure. J Am Soc Echocardiogr 26: 1033-1042. [Crossref]

12. Faxon DP, Creager MA, Halperin JL, Gavras H, Coffman JD,et al. (1980) Central and peripheral hemodynamic effects of angiotensin inhibition in patients with refractory congestive heart failure. Circulation 61: 925-930.

13. Pedersen WR, Klaassen PJ, Boisjolie CR, Pierce TA, Harris KM, et al. (2007) Feasibility of transcatheter intervention for severe aortic stenosis in patients $>$ or $=90$ years of age: aortic valvuloplasty revisited. Catheter Cardiovasc Interv Off J Soc Card Angiogr Interv 70: 149-154.

14. Vahanian A, Alfieri O, Andreotti F, Antunes MJ, Baron-Esquivias G (2012) Guidelines on the management of valvular heart disease (version 2012): The Joint Task Force on the Management of Valvular Heart Disease of the European Society of Cardiology (ESC) and the European Association for Cardio-Thoracic Surgery (EACTS). Eur Heart J 33: 2451-2496.

15. Nashef SA, Roques F, Michel P, Gauducheau E, Lemeshow S, et al. (1999) European system for cardiac operative risk evaluation (EuroSCORE). Eur J Cardio-Thorac Surg Off J Eur Assoc Cardio-Thorac Surg 16: 9-13.

16. Levey AS, Stevens LA, Schmid CH, Zhang YL, Castro AF 3rd (2009) A new equation to estimate glomerular filtration rate. Ann Intern Med 150: 604-612. [Crossref]

17. Ben-Dor I, Pichard AD, Satler LF, Goldstein SA, Syed AI, et al. (2010) Complications and Outcome of Balloon Aortic Valvuloplasty in High-Risk or Inoperable Patients. JACC Cardiovasc Interv 3: 1150-1156.

18. Khawaja MZ, Sohal M, Valli H, Dworakowski R, Pettit SJ (2013) Standalone balloon aortic valvuloplasty: indications and outcomes from the UK in the transcatheter valve era. Catheter Cardiovasc Interv 81: 366-373. [Crossref]

19. Eltchaninoff H, Durand E, Borz B, Furuta A, Bejar K, et al. (2014) Balloon aortic valvuloplasty in the era of transcatheter aortic valve replacement: Acute and long-term outcomes. Am Heart J 167: 235-240.

20. Kapadia S, Stewart WJ, Anderson WN, Babaliaros V, Feldman T, et al. Outcomes of inoperable symptomatic aortic stenosis patients not undergoing aortic valve replacement: insight into the impact of balloon aortic valvuloplasty from the PARTNER trial (Placement of AoRtic TraNscathetER Valve trial). JACC Cardiovasc Interv 8: 324-333.

21. Nwaejike N, Mills K, Stables R, Field M (2015) Balloon aortic valvuloplasty as a bridge to aortic valve surgery for severe aortic stenosis. Interact Cardiovasc Thorac Surg 20: 429-435.

22. Leon MB, Smith CR, Mack M, Miller DC, Moses JW, et al. (2010) Transcatheter aortic-valve implantation for aortic stenosis in patients who cannot undergo surgery. N Engl J Med 363: 1597-1607.

Copyright: (C2018 Calcaianu M. This is an open-access article distributed under the terms of the Creative Commons Attribution License, which permits unrestricted use, distribution, and reproduction in any medium, provided the original author and source are credited. 